\title{
Inflow Flood Simulation and Risk Analysis of Cascade Reservoirs
}

\author{
${ }^{1 \text { st }}$ Jing Huang, ${ }^{2 n d}$ Jiqing Li, ${ }^{\text {rrd }}$ Pengteng Liang \\ School of renewable energy North China Electric Power University Beijing, China
}

\begin{abstract}
The risk of flood control in cascade reservoirs reflects the possibility of unforeseen events in upstream reservoirs under certain space-time conditions during the operation of flood control. Using @ RISK software and a stochastic simulation model to simulate the inflow flood of cascade reservoirs, the flood routing of cascade reservoirs and the risk analysis of the highest water level were carried out based on the flood regulation rules of Three Gorges-Gezhouba cascade reservoirs. The results of simulation calculations show that the risk rate of the Three Gorges-Gezhouba cascade reservoir is lower than its design flood standard, which can ensure the safety of flood control.
\end{abstract}

\section{INTRODUCTION}

The risks originate from the uncertainty of the events. There are hydrological, hydraulic, dispatch methods and other uncertainties in the flood control of reservoirs, and these factors will bring about flood hazards in reservoirs [1-2]. The risk of reservoir flood control refers to the unforeseen event of high flood level or over-damage of the reservoir under certain space-time conditions, as well as the probability of its occurrence and the resulting degree of damage [3-5]. Risk analysis is to study and calculate this kind of uncertainty, and to determine the possibility of the Project crash. In the risk analysis of reservoir operation, the flood risk rate has always been a research hotspot. Many hydrographers at home and abroad have conducted a lot of research on it. M. Jin believes that only considering the risk of hydrological factors in the risk analysis is not comprehensive enough, and systematically analyzes the uncertainty of the hydraulic factors [6]. Random simulation of runoff provides new ideas for risk analysis. Y. Xiao used Gumbel-Hougaard Copula to construct a joint bivariate distribution with a P-III distribution in the edge distribution, successfully describing the flood volume and flood peak during reservoir flooding [7]. Thus, establishing a new method of random simulation of flood processes. J. Li applied a matter-element method to assess the risk of the flood control system [8]. Y. Lu use an integrated statistical and data-driven (ISD) framework was proposed for analyzing river flows and flood frequencies in the Duhe river basin in China [9]. K. Halbert analyzed the differences between local and regional flood risk analysis methods [10]. A. Fatemeh discusses the "Fragrance Analysis of Functional Nuclear Magnetic Resonance Analysis Methods" (FRAM) qualitative framework for flood risk analysis and is a useful complement to the reliability analysis method for flood risk prevention [11]. The above risk analysis only focuses on the probability of occurrence of risk events, and the flood control risk analysis of cascaded reservoirs is a highly complex system. The flood control risk analysis of cascade reservoirs needs to simulate the inflow flood of upstream and downstream reservoirs and demonstrate the flood control capacity of reservoirs based on simulation data. The risk rate of cascade reservoirs in flooding is calculated and analyzed, thus providing a basis for decision-making of reservoir flood control. This paper uses@RISK stochastic simulation software and seasonal first-order autoregressive model to simulate the runoff of cascade reservoirs. Based on the flood regulation rules of Three Gorges-Gezhouba cascade reservoirs, the flood routing and the analysis of the maximum water level risk of cascade reservoirs are studied.

\section{FLOOD STOCHASTIC SIMULATION AND RISK ANALYSIS METHOD}

\subsection{The Model of Stochastic Simulation of Flow Flood}

The stochastic simulation method is an advanced method developed from the current hydrological analysis method. It can overcome the deficiencies of traditional methods such as measured sequence method and design process line method, and is more objective, comprehensive and more adaptable. Its notable features are:

1> The stochastic simulation method can fully characterize the characteristics of the statistical changes of hydrological phenomena, and the different models can show different emphasis;

\footnotetext{
*Corresponding author:1400110642@qq.com jqli6688@163.com812554069@qq.com
} 
2> The stochastic simulation method can simulate a large number of hydrological sequences, and the frequency curve of water indexes used for engineering planning and design can be obtained conveniently and reasonably through simulation calculation.

3> The stochastic simulation method can simulate a large number of sequences, and these sequences can represent all the possible occurrences of future hydrological phenomena.

1) The Simulation of P-III Stochastic Variable

In terms of the selection of hydrological frequency curve types, there are great differences in the world, and more than 20 types are commonly used. Since the 1960s, by fitting and verifying the distribution rules of extreme flood data, it is believed that the P-III distribution curve can better fit the flood series of most rivers in China. Therefore, China's water conservancy and hydropower project hydrological calculation code recommends the use of P-III distribution. The probability density function of PIII stochastic variable is:

$$
f(x)=\frac{\beta^{\alpha}}{\Gamma(\alpha)}\left(x-a_{0}\right)^{\alpha-1} e^{-\beta\left(x-a_{0}\right)}
$$

$\left(\mathrm{x} \geq \mathrm{a}_{0} ; \alpha, \beta>0\right)$

First, find the three basic parameters of P-III distribution $\mathrm{E}(\mathrm{X}), \mathrm{C}_{\mathrm{v}}, \mathrm{C}_{\mathrm{s}}$ :

$$
\begin{gathered}
E(x)=\frac{1}{n} \sum_{i=1}^{\mathrm{n}} x_{i} \\
C_{v}=\sqrt{\frac{1}{n-1} \sum_{i=1}^{n}\left(K_{\mathrm{i}}-1\right)^{2}} \\
C_{s}=\frac{\sum_{i=1}^{n}\left(K_{\mathrm{i}}-1\right)^{3}}{(n-3) C_{v}^{3}}
\end{gathered}
$$

Then calculate the density function parameters $\alpha, \beta$ and $\mathrm{a}_{0}$ :

$$
\left\{\begin{array}{l}
\alpha=\frac{4}{C_{S}^{2}} \\
\beta=\frac{2}{E(X) C_{v} C_{s}} \\
a_{0}=E(X)\left(1-\frac{2 C_{v}}{C_{s}}\right)
\end{array}\right.
$$

Assume that $\alpha$ satisfies $\alpha=\gamma+\lambda$, where $\gamma$ is a negative integer and $0<\lambda<1$. Finally, a simulated hydrological sequence is generated by the rejection technique sampling method. The specific steps are as follows:

$1>$ In the interval $[0,1]$, generate $n$ random numbers $u_{i}$ that are uniformly distributed;

$$
2>\text { Order } \mathrm{y}=-\sum_{i=1}^{n} \ln u_{i} \text {; }
$$

$3>$ In the interval $[0,1]$, generate random numbers $u_{n+1}$, $\mathrm{u}_{\mathrm{n}+2}, \mathrm{u}_{\mathrm{n}+3}$ obeys uniform distribution;

$4>\operatorname{Order} S_{1}=\mathrm{u}_{n+1}^{1 / n}, \quad S_{2}=u_{n+2}^{1 / 1-\alpha} ;$

5> If $\mathrm{S}_{1}+\mathrm{S}_{2} \leq 1$, make $\mathrm{t}=\mathrm{S}_{1}\left(\mathrm{~S}_{1}+\mathrm{S}_{2}\right)$ and $\mathrm{x}=-t \ln u_{n+3}$, otherwise, go back to step 3 ;

$6>$ Let $\mathrm{z}=\mathrm{x}+\mathrm{y}$, and generate random number $\mathrm{z}^{\prime}=\frac{z}{\lambda}+a_{0}$ follow the P-III distribution;

When $\gamma$ is large, using a rejection technique method to generate sample values requires the use of multiple pseudo-random numbers. This will make the method complex and not economical. At this time, an approximate formula can be used to generate the standardized P-III variable $\delta_{\mathrm{i}}$ :

$$
\delta_{\mathrm{i}}=\frac{2}{C_{s}}\left(1+\frac{C_{s} t_{i}}{6}-\frac{C_{S}^{2}}{36}\right)^{3}-\frac{2}{C_{s}}
$$

Where $t_{i}$ is the standard normal random numbers. Finally using Eq.7 to generate P-III random variable sample values $\mathrm{x}_{\mathrm{i}}$;

$$
\mathrm{x}_{i}=\bar{x}\left(1+C_{v} \delta_{i}\right)
$$

\section{2) Inflow Flood Simulation for Cascade Reservoir}

Risk analysis of flood control in cascade reservoirs involves not only flooding factors such as flood peak flow, total flood volume, and the time of occurrence of flood peaks, but also the size of reservoirs such as flood control capacity, flood discharge capacity, and reservoir operation scheduling rules. It is difficult to directly calculate the risk rate using the analytical method. Generally, it can only be analyzed by the stochastic simulation method. Analysis ideas are as follows:

$1>$ Using relevant methods and based on historical flood series, generate artificial runoff sequence $\mathrm{Q}_{\mathrm{t}}$;

2> Using $Q_{t}$ as input, combined with reservoir operating conditions and scheduling rules, reservoir storage process $\mathrm{V}_{\mathrm{t}}$, dam front water level process $\mathrm{Z}_{\mathrm{t}}$, and discharge flow process $\mathrm{q}_{\mathrm{t}}$ can be obtained;

$3>$ Changing the flood design frequency, reservoir parameters $\mathrm{k}$ and scheduling rules $\mathrm{R}$, can get different $\mathrm{V}_{\mathrm{t}}$, $\mathrm{Z}_{\mathrm{t}}$ and $\mathrm{q}_{\mathrm{t}}$;

$4>$ The statistical output series can obtain the distribution function of the reservoir discharge flow or the front water level distribution function.

\subsection{Stochastic Simulation with @RISK}

(a)RISK is an Excel-based simulation modeling application developed by Palisade. It allows users to use the probability distribution model in the modeling process, and can use Monte Carlo simulation to perform risk analysis on the input data and derive the possibility of risk occurrence. The @ RISK toolbar is shown in Fig. 1. The following functions can be accomplished through the toolbar: 
$1>$ It is easy to generate observations based on the most important probability distributions;

$2>$ Users can designate any cell or cell area as output, and can summarize the indicators (average, standard deviation, percentage, etc.) through a copy or graphical presentation;

$3>$ The simulation function can generate random numbers in each random input cell in the model, recalculate the worksheet and record the values in all output cells;

$4>$ Other functions.

The general steps to simulate flood using @ RISK software are as follows:

$1>$ Define the distribution of stochastic variable values. The user can directly select the "Define Distribution" button in the toolbar. The stochastic variable in the model obey the standard normal distribution.

$2>$ The distribution of the stochastic variables obeyed is transformed from the standard normal distribution into the standard P-III distribution according to the relevant formula. Combine statistical parameters of historical runoff until the simulated value is obtained;

3> The analog value column is set to "add output" state, the user can observe each analog value and the overall statistical parameters after the simulation;

4> The number of iterations and simulations can be set in the software simulation toolbar. Click the "Start Simulation" button to simulate the set analog value and view the corresponding simulation result in the software result toolbar.



Fig. 1. Toolbar interface of @RISK stochastic simulation software

\subsection{The Risk Rate of Reservoir Flood Control}

The flood control risk of reservoirs is the probability that the dam will not be able to safely conduct flood control when it encounters a flood at a certain design frequency, and the risk of damage has occurred. The risk of reservoir flood control is the probability that the reservoir will not be able to safely carry out flood control or damage to the dam when it encounters a flood at a certain design frequency. The water level corresponding to a certain risk event in the reservoir is $Z$. $Z_{\text {Max }}$ is the maximum water level of the reservoir to ensure that this risk event does not occur. In a flooding process, if the water level exceeds the $\mathrm{Z}_{\mathrm{Max}}$ of the reservoir's limit, it can be considered as a risk event occurring in the reservoir. The limit state equation for this risk event can be expressed as:

$$
Z-Z_{\max }=0
$$

Therefore, the risk rate of this incident can be expressed in the frequency of the reservoir's maximum water level exceeding the reservoir's limit water level during the flood control operation:

$$
P_{\mathrm{f}}=P\left\{Z>Z_{d}\right\}=P\left\{Z^{\prime}>0\right\}=\int_{0}^{n} f(Z) d z
$$

Where $Z^{\prime}=Z-Z_{\max } ; n$ is the total amount of statistical data.

When the frequency of floods is sufficient, a large number of $Z^{\prime}$ can be obtained. By arranging $Z^{\prime}$ in descending order and counting the frequency of occurrence of $Z^{\prime}$ less than $Z^{\prime}$, the probability distribution curve of $Z^{\prime}$ can be obtained. In general, the more floods in statistics, the more accurate the resulting probability distribution curve will be. Risk analysis can be performed by using $Z^{\prime}$ probability distribution map.

\section{CAse study}

\subsection{Introduction of Cascade Reservoirs}

The Three Gorges Water Control Project is a large-scale water conservancy project built on the middle and upper reaches of the Yangtze River and is distributed on the mainstream of the Yangtze River from Chongqing to Hubei Province. The dam of the Three Gorges Hydropower Station is located in Sandouping, Yiling District, Yichang City, and constitutes a cascade reservoir dispatching structure with the Gezhouba Hydropower Station $38 \mathrm{~km}$ downstream of it. The main task in early stage of operation of the Three Gorges Water Conservancy Project is to gradually bring into play the comprehensive benefits of flood control, power generation and shipping under the conditions that ensure the safety of the completed projects and construction. The normal pool level of the Three Gorges Reservoir is $175 \mathrm{~m}$, the restricted water level in flood period is $145 \mathrm{~m}$, the dead water level is $145 \mathrm{~m}$, and flood storage capacity is 22.15 billion cubic meters. In order to meet the demand for flood control, reservoirs generally begin to reduce the water level in front of the dam in late May of each year and drop to $145 \mathrm{~m}$ around June 10 . The flood season is from mid-June to the end of September. Therefore, the reservoir began to store water from the beginning of October, and the water level of the reservoir reached $175 \mathrm{~m}$ at the end of the month. Gezhouba Hydropower Station is located at the end of the Three Gorges of the Yangtze River. Its main task is to carry out counterregulation of the unsteady flow discharged by the Three Gorges water-control project, and to give full play to the benefits of power generation under the premise of ensuring the safety and patency of navigation[12]. The daily operation water level of Gezhouba Hydropower 
Station is in the range of $63-66 \mathrm{~m}$ and the water level for check flood is $67 \mathrm{~m}$.

\subsection{Statistical Calculation and Simulation of Runoff in Historical Storage}

The statistical calculation of the data of the inflow runoff from the Three Gorges Reservoir from 1877 to 2015 was carried out by dividing the time period by month in the non-flood season (October - April of the following year) and the time by day in the flood season(May-September). @ RISK software was used to simulate the runoff from the Three Gorges Reservoir based on statistical results. Taking non-flood period as an example, the statistical results are shown in Table 1. Taking the inflow flood in December for example, the simulation results are shown in Fig 2. By comparing the actual statistical results with the simulation results, it can be concluded that the average value of 10,000 simulation values is $5,929.00 \mathrm{~m}^{3} / \mathrm{s}$, which is equal to the average of the actual statistical results; Both the standard deviation $\sigma_{\mathrm{x}}$ and the skewness $\mathrm{C}_{\mathrm{s}}$ are very close to the actual values. It can be seen that the runoff simulation using@RISK software works well.

TABLE 1. STATISTICS OF HISTORICAL INFLOW RUNOFF PARAMETERS IN THE THREE GORGES RESERVOIR

\begin{tabular}{ccccccc}
\hline Statist & & & & & & \\
Period & $\mathrm{E}(\mathrm{X})$ & $\sigma_{\mathrm{x}}$ & $\mathrm{C}_{\mathrm{v}}$ & $\mathrm{C}_{\mathrm{s}}$ & $\gamma 1, \tau$ & $\psi_{1, \tau}$ \\
\hline Oct. & & & & & & \\
\hline & 1860 & 3921 & 0.211 & 0.308 & 0.575 & 0.420 \\
Nov. & 1021 & 1902 & 0.186 & 0.516 & 0.544 & 0.081 \\
& 7 & & & & & \\
Dec. & 5929 & 682 & 0.115 & 0.104 & 0.568 & 0.178 \\
Jan. & 4361 & 476 & 0.109 & 0.747 & 0.039 & 0.027 \\
Feb. & 3953 & 445 & 0.113 & 0.246 & 0.699 & 0.348 \\
Mar. & 4442 & 769 & 0.173 & 0.338 & 0.602 & 0.264 \\
Apr. & 6645 & 1537 & 0.231 & 0.723 & 0.620 & 0.204 \\
\hline
\end{tabular}

\subsection{Risk Analysis of Three Gorges-Gezhouba Cascade Reservoirs}

1) The Flood Routing Rules of Three Gorges-Gezhouba Cascade Reservoirs

In flood season, the Three Gorges Reservoir needs to reserve 22.15 billion cubic meters of flood storage capacity to ensure effective control and regulation of floods. In general, the use of 22.15 billion cubic meters of flood storage capacity control is shown in Table 2.

Table 2. Application methods of flood storage capacity control in the Three Gorges Reservoir

\begin{tabular}{cccc}
\hline $\begin{array}{c}\text { Gradin } \\
\mathrm{g}\end{array}$ & $\begin{array}{c}\text { Storage } \\
\text { Capacity } \\
\left(10^{8} \mathrm{~m}^{3}\right)\end{array}$ & $\begin{array}{c}\text { Limit } \\
\text { Discharge } \\
\text { Flow } \\
\left(\mathrm{m}^{3} / \mathrm{s}\right)\end{array}$ & Purpose \\
\hline 1 & $\leq 140$ & 30,000 & $\begin{array}{c}\text { Ensure the } \\
\text { security of most } \\
\text { farmland along } \\
\text { the river } \\
\text { Ensure the safety } \\
\text { of the } \\
\text { embankment }\end{array}$ \\
\hline
\end{tabular}

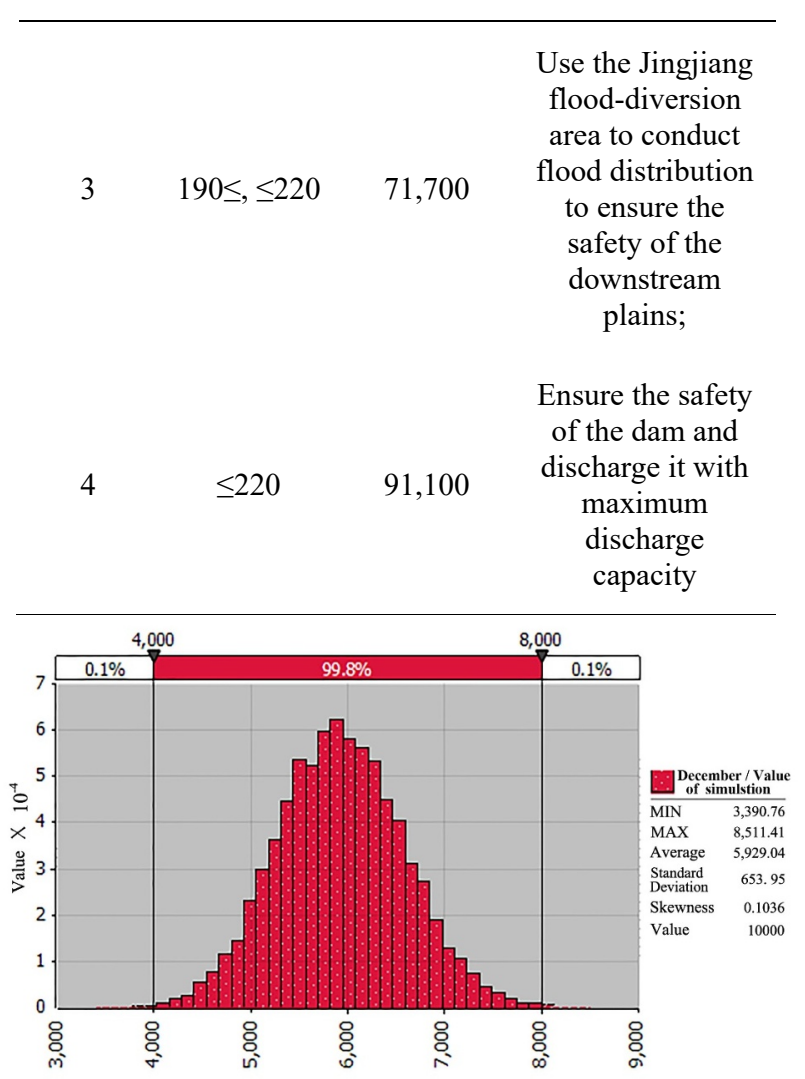

Fig. 2. Results of flood simulation of the Three Gorges Reservoir in December

The operating level of Gezhouba is $63-66 \mathrm{~m}$. As a runof-river hydropower station, if the difference between the outbound flow rate and the inbound flow rate is too large, it may cause a significant change in the water level and threaten the operation safety of the reservoir.

\section{2) Simulation Scheme of Flood Routing}

This paper will set the start time of the flood routing to June 10, set the end time to September 30, and set the water level to $145 \mathrm{~m}$. The simulation results of the seasonal first-order autoregressive model were used as the process of inflows. The flood simulation calculations were performed in conjunction with the Three GorgesGezhouba cascade reservoir flood routing rules. In the above process, @RISK software was run 10 times, and the number of simulations was increased from 10,000 times to 100,000 times each time. The result of the maximum water level distribution for each run was obtained. After 10 simulations are completed, the maximum flood level distribution of the two reservoirs can be obtained. 


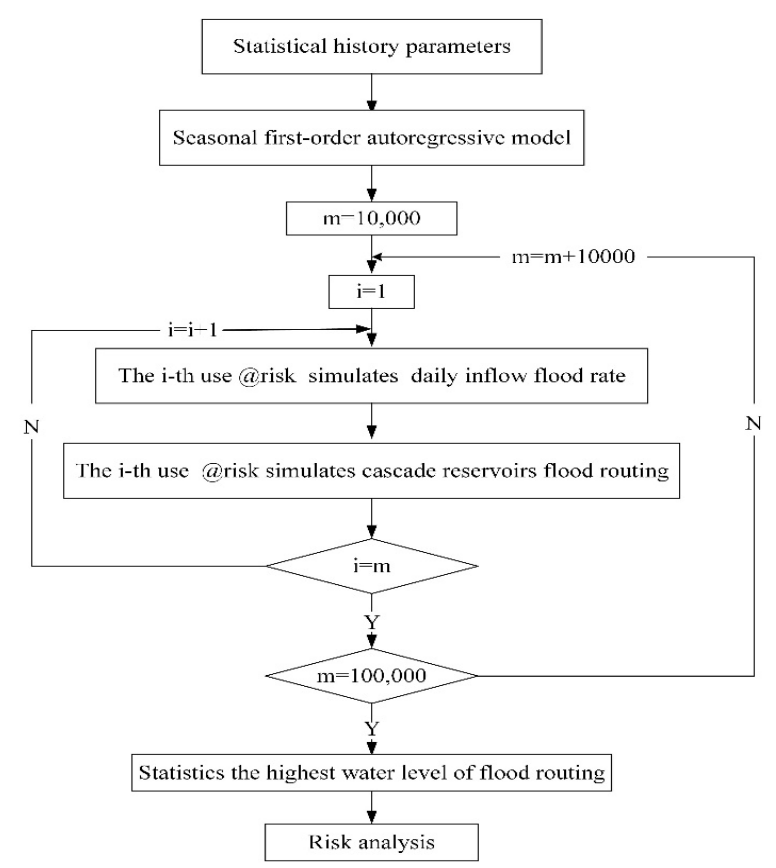

Fig. 3. Flow of Flood Risk Analysis

3) Simulation Results and Risk Analysis

Taking the flood routing with $\mathrm{m}=10,000$ as an example, the average maximum flood level of the Three Gorges Reservoir is $163.28 \mathrm{~m}$, the minimum is $146.96 \mathrm{~m}$, and the maximum is $177.40 \mathrm{~m}$. After the partial enlargement of the distribution map, it can be seen that the highest flood level exceeds the water level for design flood $(175 \mathrm{~m})$ four times, and the flood level exceeds the water level for check flood $(185 \mathrm{~m}) 0$ times. Fitting the distribution results, as shown in Fig. 4, is in accordance with the normal distribution of $Z_{\mathrm{sx}, \max } \sim \mathrm{N}(163.30,3.59)$, and the probability density function is shown in formula 10:

$f\left(Z_{S X, \max }\right)=\frac{1}{3.58 \sqrt{2 \pi}} e^{-\frac{\left(Z_{S X, \max }-163.28\right)^{2}}{25.63}}$

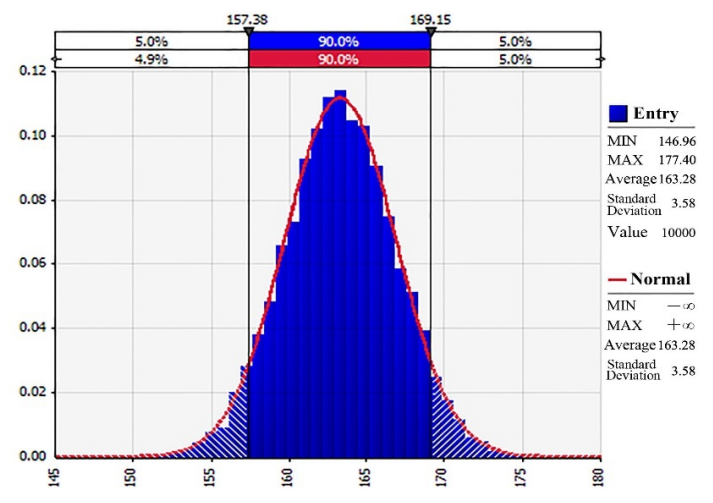

Fig. 4. Distribution and fitting of the highest flood level in the Three Gorges Reservoir

After the 10,000 flood simulations in the Gezhouba Reservoir, the maximum flood level averaged $64.8 \mathrm{~m}$ with a standard deviation of $0.630 \mathrm{~m}$. The highest water level accounted for $96.9 \%$ of the total simulation times in the range of $63-66 \mathrm{~m}$, and the abnormal operation water level exceeding $66 \mathrm{~m}$ was 282 times, accounting for $2.8 \%$, and 21 times less than $63 \mathrm{~m}$, accounting for $0.2 \%$.

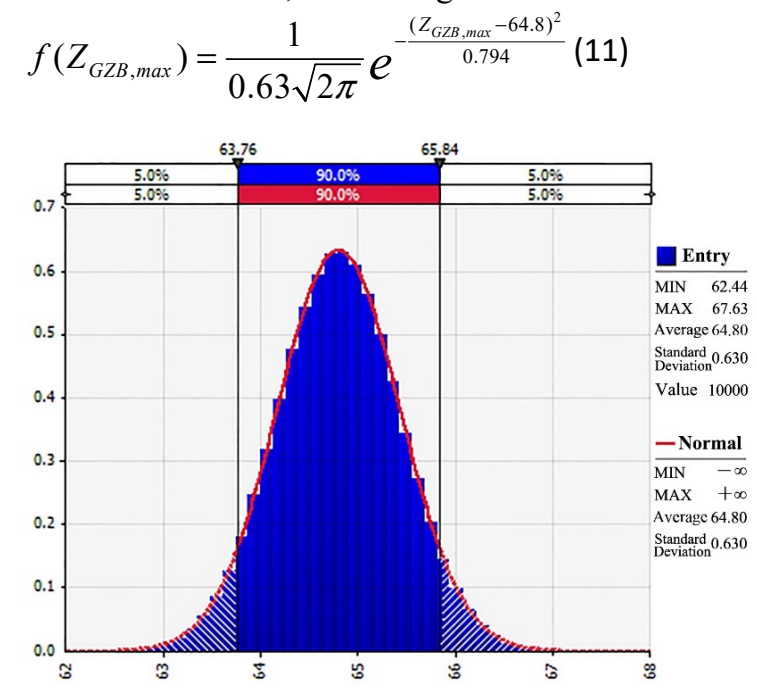

Fig. 5. Distribution of maximum water level in Gezhouba Reservoir and its fitting result

After using the @RISK software to perform the flood simulation calculations for the Three Gorges-Gezhouba Cascade Reservoir for 10 times, the frequency distribution of the maximum flood level over the normal operation water level is shown in Table 3.

Table 3. Statistics of simulation results and risk rates of the Three Gorges-Gezhouba cascade reservoirs

\begin{tabular}{|c|c|c|c|c|}
\hline \multirow{2}{*}{ Simulation times } & \multicolumn{2}{|c|}{ Three Gorges } & \multicolumn{2}{|c|}{ Gezhouba } \\
\hline & $>175 \mathrm{~m}$ & $>185 \mathrm{~m}$ & $<63 \mathrm{~m}$ & $>66 \mathrm{~m}$ \\
\hline 10000 & 4 & 0 & 21 & 282 \\
\hline 20000 & 10 & 1 & 39 & 540 \\
\hline 30000 & 15 & 2 & 64 & 820 \\
\hline 40000 & 22 & 3 & 84 & 1077 \\
\hline 50000 & 30 & 3 & 99 & 1341 \\
\hline 60000 & 39 & 4 & 117 & 1627 \\
\hline 70000 & 45 & 4 & 135 & 1887 \\
\hline 80000 & 51 & 5 & 153 & 2156 \\
\hline 90000 & 59 & 6 & 171 & 2430 \\
\hline 100000 & 66 & 7 & 185 & 2712 \\
\hline Average risk rate & $0.06 \%$ & $0.006 \%$ & $0.20 \%$ & $2.71 \%$ \\
\hline
\end{tabular}

According to Table 3, the average risk rate of the water level for design flood(175m) of the Three Gorges Reservoir is $0.06 \%$, and the average risk rate of the water level for check flood $(185 \mathrm{~m})$ is $0.006 \%$. The result is in line with the reservoir design and calibration standards. 
The safe operating water level of Gezhouba is $63-66 \mathrm{~m}$, and the average risk rate of the highest flood level below the minimum allowed water level $(63 \mathrm{~m})$ is $0.2 \%$, and the average risk rate greater than the maximum allowed water level $(66 \mathrm{~m})$ is $2.71 \%$. In fact, Gezhouba Reservoir does not have strict flood control requirements. When floods with high flood peaks are encountered and the water level exceeds the maximum allowable operating water level, as long as the discharge flow is increased in time and the water level falls back to the safe range as soon as possible, it will not cause too great a threat to the dam.

\section{CONCLUSION}

This paper simulates and assesses the flood pressures of cascade reservoirs that may occur in the future by simulating the possible floods in cascade reservoirs, and tests the flood control effects and flood control standards of cascade reservoirs. A seasonal first-order autoregressive model was used to simulate runoff of inflow. The Monte Carlo risk analysis method was used to analyze the flood risk of the Three Gorges-Gezhouba cascade reservoirs. Using @RISK software for analysis, the flood simulation results show that: The average risk rate of the Gezhouba operating water level below the minimum allowable operating water level is $0.2 \%$, and the average risk rate above the maximum allowable operating water level is $2.71 \%$. It shows that the Three GorgesGezhouba Cascade Reservoirs can ensure the safety of the downstream flood protection objects in the event of a flood that meets the standard of one thousand years and meets the standard of thousands of years. It shows that the Three Gorges-Gezhouba cascade reservoirs can ensure the safety of the downstream flood protection objects when it encounters design floods up to and including the standard of 10,000 years.

\section{ACKnowledgment (Heading 5)}

This study was financially supported by National Key Projects of China "Water resources efficient development and utilization" (2016YFC0402208, 2016YFC0401903, 2017YFC0405900) and National Natural Science Foundation of China (No. 51641901). The authors would like to give special thanks to the anonymous reviewers.

\section{REFERENCES}

1. H. Heping, S. Shonghao and L. Zhidong, "A View from ' 98 Flood; From Control to Disaster Risk
Management", Water Resources and Hydropower Engineering, vol. 30, pp. 3-5, 1999.

2. D. Sheng, W. Teng, "Risk assessment of flood control water project", Journal of Hydraulic Engineering, vol. 09, pp. 19-24, 2003.

3. S. Binfang, "Flood Risk Management in the United Kingdom", Express Water Resources \& Hydropower Information, vol. 27, pp. 1-10, 2006.

4. Z. Shenghong, "Flood Control Dispatch and Flood Disaster Management in the United States", Haihe Water Resources, vol. 4, pp. 40-41, 2000.

5. X. Ming, "Risk Research of Flood Protection for Three Gorges Project", Water Resources and Hydropower Engineering, vol. 30, pp. 39-42, 1999.

6. J. Ming, "Hydraulic Uncertainties and Their Effects on Risk Analysis of Levee or Spillway Systems", Journal of Hohai University (Natural Sciences), vol. 1, pp. 40-45, 1991.

7. X. Yi, G. Liansheng, X. Huali, “A New Random Simulation Method for Constructing Synthetic Floof Hydrographs", Advanced Engineering Sciences, vol. 39, pp. 55-60, 2007.

8. L. Jiqing, J. Changming, Z. Yushan and W. Liping, "Matter-element Model of Integrated Risk Assessment for Flood Control Systems", International Journal of risk assessment and management, vol. 8, pp. 342-352, 2008.

9. Y. Lu, X.S. Qin and Y.J. Xie, "An integrated statistical and data-driven framework for supporting flood risk analysis under climate change", Journal of Hydrology, vol. 533, pp. 28-39, 2016.

10. K. Halbert, C.C. Nguyen, O. Payrastre and E. Gaume, "Reducing uncertainty in flood frequency analyses: A comparison of local and regional approaches involving information on extreme historical floods", Journal of Hydrology, vol. 541, pp. 90-98, 2016.

11. F. Anvarifar, M. Z. Voorendt, C. Zevenbergen and W. Thissen, "An application of the Functional Resonance Analysis Method (FRAM) to risk analysis of multifunctional flood defences in the Netherlands", Reliability Engineering \& System Safety, vol. 158, pp. 130-141, 2017.

12. W. Bixin, "Analysis on key data for dispatching of Three Gorges-Gezhouba Cascaded Water Control Project", Water Resources and Hydropower Engineering, vol. 46, pp. 100-103, 2015. 